\title{
EMBLEMAS E RITUAIS: RECONSTRUINDO A HISTÓRIA DA ESCOLA DE ENFERMAGEM HERMANTINA BERALDO
}

\author{
Emblems and Rituals: Rebuilding the History of \\ Hermantina Beraldo School of Nursing \\ Emblemas y Rituales: Reconstrucción de la Historia \\ de la Escuela de Enfermería Hermantina Beraldo
}

Josefar Reis de Toledo ${ }^{1}$
Maria Aparecida de Araújo

\author{
Tânia Cristina Franco Santos² \\ Antônio José de Almeida Filho ${ }^{4}$
}

\begin{abstract}
Resumo
Estudo histórico-social. Objeto: emblemas e rituais instituídos pela Escola de Enfermagem Hermantina Beraldo no período de 1947 a 1950. Objetivos: caracterizar a escola; enumerar os emblemas e rituais por ela utilizados e comentar as implicações da utilização desses emblemas e rituais. As fontes primárias foram documentos escritos e fotográficos pertencentes ao acervo da escola e ao acervo pessoal da professora Maria Aparecida Araújo. As fontes secundárias focalizam a História da Enfermagem Brasileira, a História do Brasil e a história da própria escola. A análise dos dados, feita com base em estudos relativos à temática do estudo, evidenciou que os emblemas e rituais, de inspiração religiosa e militar, instituídos pela escola, apontavam modelos a serem seguidos, inculcando atributos como hierarquia e disciplina, de modo a favorecer a construção da identidade da enfermeira diplomada pela Escola de Enfermagem Hermantina Beraldo.
\end{abstract}

Palavras-chave: História da Enfermagem. Escolas de Enfermagem, Emblemas e Insígnias. Rituais.

\begin{abstract}
Historical and social study. Object: emblems and rituals instituted for the School of Nursing Hermantina Beraldo in the period of 1947 the 1950. Objectives: to characterize the School of Nursing Hermantina Beraldo; to enumerate the emblems and rituals used for the School and to comment the implications of the use of these emblems and rituals. The primary sources had been documents written and photographic pertaining to the quantity of the School of Nursing Hermantina Beraldo and to the personal quantity of the teacher Maria Aparecida de Araújo. The secondary sources focus the History of the Brazilian Nursing, History of the School of Nursing Hermantina Beraldo and the History of Brazil. The analysis of the data, made on the basis of relative studies to the thematic one of the study evidenced that the emblems and rituals, of religious and military inspiration, instituted for the School of Nursing Hermantina Beraldo pointed models to be followed, inculcating attributes as hierarchy and disciplines, in order to favored the construction of the identity of the diploma nurse for the School of Nursing Hermantina Beraldo.
\end{abstract}

Keywords: History of Nursing. Schools, Nursing. Emblemas and Insignia. Ceremonial Behavior.

\section{Resumen}

Estudio histórico y social. Objeto: emblemas y rituales instituidos para la escuela del oficio de enfermera Hermantina Beraldo en el período de 1947 el 1950. Objetivos: caracterizar la escuela; enumerar los emblemas y los rituales usados por la escuela y comentar las implicaciones del uso de estos emblemas y rituales. Las fuentes primarias fueron documentos escritos y material fotográfico de la escuela de enfermería Hermantina Beraldo y la relación personal de la profesora Maria Aparecida de Araújo. Las fuentes secundarias enfocan la historia del oficio de enfermera brasileño, la historia de la escuela enfermería Hermantina Beraldo y la historia del Brasil. El análisis de los datos, fue hecho en base de estudios relativos al tema del estudio que evidenció los emblemas y los rituales, de la inspiración religiosa y militar, instituidos para la escuela de enfermería Hermantina Beraldo los modelos que se seguirán, las cualidades inculcando jerarquía y disciplinas, para favorecer la construcción de la identidad de la enfermera del graduado para la escuela del oficio de enfermera Hermantina Beraldo. 


\section{INTRODUÇÃO}

0 presente estudo tem como objeto os emblemas e rituais instituídos pela Escola de Enfermagem Hermantina Beraldo (EEHB) durante o processo de formação das duas primeiras turmas. 0 recorte temporal engloba o período de 1947 a 1950. 0 marco inicial representa o início do seu funcionamento; e 0 final, a formatura da $1^{\mathrm{a}}$ e $2^{\mathrm{a}}$ turmas de enfermeiras.

A EEHB incorporou rituais e emblemas inventados pela Escola de Enfermagem Anna Nery (EEAN), adotados pela Escola de Enfermagem Carlos Chagas (EECC) desde a sua criação em 1933.

É pertinente esboçar que, desde o início do funcionamento da EEAN, em 1923, e mesmo após sua inserção na Universidade do Brasil em 1937, seus emblemas e rituais foram adotados por outras escolas, podendo ser considerada como centro difusor de "tradições inventadas" premissa de que esses rituais e emblemas constituíram importantes instrumentos simbólicos de visibilidade da imagem da enfermeira diplomada pela nascente Escola. No entanto, existe pouca informação disponível sobre como tais emblemas e rituais foram mobilizados na construção da imagem da enfermeira diplomada pela Escola mineira.

Por tradição inventada entende-se:

"um conjunto de práticas normalmente reguladas por regras tácitas ou abertamente aceitas; tais práticas, de natureza ritual ou simbólica, visam inculcar certos valores e normas de comportamento através da repetição, o que implica automaticamente, uma continuidade em relação ao passado...." 2:9.

Tais emblemas e rituais, ao longo da trajetória da História da Enfermagem no Brasil, passaram a fazer parte do cotidiano das instituições de ensino de Enfermagem.

0 interesse em elaborar este estudo surgiu após Aula Inaugural do primeiro semestre/2003, proferida pela Dra. Tânia Cristina Franco Santos, intitulada "Significado dos emblemas e rituais na formação da identidade da enfermeira brasileira: uma reflexão após oitenta anos", bem como depois de observação de fotos antigas localizadas na disser tação de mestrado intitulada "História da Escola de Enfermagem Hermantina Beraldo: Gestão Celina Viegas", de Maria Aparecida de Araújo, defendida em 2002. Também, o fato de ser natural da cidade Juiz de Fora Minas Gerais influenciou nesta escolha. E, finalmente, a motivação para pôr em prática este estudo deve-se a minha inserção no Núcleo de Pesquisa de História de Enfermagem Brasileira, em 2003, à época aluno de graduação.

0 estudo é relevante porque contribui para a História da Enfermagem Brasileira, em especial para a história da Escola de Enfermagem Hermantina Beraldo. Ademais, a recuperação dos emblemas e rituais, mediante o resgate de documentos históricos, contribui para uma melhor compreensão das estratégias mobilizadas pela referida Escola, na construção da imagem da enfermeira para a sociedade.

\section{FONTES E METODOLOGIA}

Trata-se de um estudo histórico-social vinculado ao Projeto de Pesquisa intitulado "Emblemas e rituais na formação da identidade da enfermeira brasileira", aprovado pelo Comitê de Ética e Pesquisa da Escola de Enfermagem Anna Nery/Hospital Escola São Francisco de Assis, em 31 de agosto de 2004, atendendo ao previsto na Resolução 196/96 do Conselho Nacional de Saúde.

0 estudo utilizou como fontes primárias documentos escritos (ofícios, telegramas, decretos-lei e o convite de formatura) e fotográficos pertencentes ao acervo da escola e ao acervo pessoal da professora Maria Aparecida Araújo e colaboradores ${ }^{a}$, de sua dissertação de mestrado.

As seis fotografias selecionadas das 35 pertencentes aos acervos supracitados para o estudo em tela referem-se à fachada da escola, por ocasião de sua inauguração e posteriores sedes; a Sessão Solene de Colação de Grau da Turma denominada "As Pioneiras" e o Desfile Cívico em Comemoração ao Centenário de Aniversário da cidade de Juiz de Fora. Na escolha das fotos, levou-se em consideração sua relação com o objeto de estudo, conforme o recorte temporal proposto. Inicialmente, procedeu-se à descrição do texto fotográfico, contemplando: cenário, o tema da foto, a data, os emblemas, os rituais e pessoas presentes no espaço fotográfico.

As fontes secundárias constituem-se em livros, dissertações, teses e artigos de periódicos que focalizam a História da Enfermagem Brasileira, a História da Escola de Enfermagem Hermantina Beraldo, a História do Brasil, em especial de Minas Gerais e de Juiz de Fora.

A análise dos dados foi feita com base em pesquisas relativas à temática do estudo, associando as fotografias aos documentos escritos, ampliando o enfoque através do respaldo teórico e construindo, desta forma, um conjunto de informações que permitiu uma compreensão mais profunda da realidade, favorecendo 0 alcance dos objetivos, quais sejam: caracterizar a Escola de Enfermagem Hermantina Beraldo; enumerar os emblemas por ela utilizados; e comentar as implicações desses emblemas e rituais para a Escola.

\section{A ESCOLA DE ENFERMAGEM HERMANTINA BERALDO}

$\mathrm{Na}$ década de 1940, por ocasião da segunda guerra mundial, houve no Brasil um crescimento dos setores urbano e industrial, ocorrendo uma nova expansão da saúde pública. 0 Serviço Especial de Saúde Pública (SESP) foi criado, tendo como objetivo principal a prestação de assistência aos trabalhadores na extração da borracha, matéria-prima exportada para utilização na guerra. Porém, existia uma forte demanda da assistência essencialmente hospitalar, exigindo uma maior qualificação dos trabalhadores da enfermagem ${ }^{3}$. A Enfermagem passou a ter um novo campo de atuação, atendendo a uma nova perspectiva de mercado de trabalho, decorrente da medicalização da assistência, que se encontrava em expansão $0^{4}$.

No que tange aos aspectos relativos à expansão do número de escolas de enfermagem conforme modelo anglo-americano, foram criadas 24 escolas de enfermagem: nove católicas, três ligadas a hospitais evangélicos, seis estaduais, três federais, duas da Cruz Vermelha e uma municipal, no período 1923 a $1949^{5}$. Para que seus cursos fossem reconhecidos em todo 0 território nacional, deveriam solicitar ao Ministério de Educação 
e Saúde Pública a equiparação conforme o Decreto-lei ${ }^{0}$ 20.109, de 15 de junho de 1931. Nesse decreto, tratava-se de alguns requisitos: ter organização moldada na escola padrão, especialmente no que diz respeito aos seguintes pontos: a direção da escola ficar a cargo de uma enfermeira diplomada, com curso de aperfeiçoamento e experiência de ensino e administração em institutos similares; condições de admissão de alunos; a duração do curso e organização, e programação desse curso, e também disporem de hospital para o ensino prático, que incluía as clínicas de cirurgia, médica, obstetrícia, pediatria e doenças contagiosas, em hospital de, no mínimo, 100 leitos $^{6}$.

Após a queda de Getúlio Vargas, término do período histórico denominado Estado Novo, a organização da política mineira, durante um período de nove meses, através de decisão do Presidente da República, General Eurico Gaspar Dutra, nomeou quatro interventores para governar Minas Gerais.

A terceira Escola de Enfermagem de Minas Gerais, EEHB, nasceu no bojo da Reforma da Saúde Pública de Minas Gerais através do Decreto-lei $n^{0} 1.751$, de 3 de junho de 1946, assinado pelo interventor do Estado de Minas Gerais, - Dr. João Tavares Correa Beraldo. 0 referido decreto possibilitou ainda a criação de Escolas de Saúde Pública, cursos gerais e especiais de Saúde Pública ${ }^{7}$.

Na época, o Dr. Alvino Moreira de Paula, médico e secretário de saúde de Minas Gerais, previa a impossibilidade de realização da Reforma da Saúde Pública em Minas Gerais sem o auxílio de enfermeiras bem preparadas, com formação profissional segura e eficiente. Dentro desse contexto, Araújo cita Viegas:

o Dr. João Ribeiro Villaça, médico formado pela Universidade do Brasil, nascido em Juiz de Fora e chefe da Clínica Cirúrgica da Santa Casa de Misericórdia de Juiz de Fora, almejava a abertura de uma escola de Enfermagem na cidade ${ }^{8: 39}$.

Em Minas Gerais, nessa ocasião, havia somente duas escolas de Enfermagem: a Escola de Enfermagem Carlos Chagas (1933) e a Escola de Enfermagem Hugo Wenerck (1946) ${ }^{4}$. 0 número de enfermeiras diplomadas por essas escolas anualmente não era suficiente para atender às necessidades de expansão e ampliação dos vários serviços de saúde a serem criados no Estado, gerando a necessidade da fundação de novas escolas.

A cidade de Juiz de Fora foi escolhida para sede da escola, não somente por ser a segunda em população do Estado de Minas Gerais, mas também pela localização afastada de Belo Horizonte, podendo atender às necessidades de outra microrregião do Estado, a próspera Zona da Mata, conhecida como a Manchester Mineira, devido ao seu desenvolvimento industrial, principalmente no setor têxtil. Além disso, Juiz de Fora era um centro cultural e possuidor de várias escolas de nível superior e vários hospitais tais como a Santa Casa de Misericórdia de Juiz de Fora, Casa de Saúde e Maternidade de Juiz de Fora, Maternidade Santa Therezinha, Dispensário Eduardo Menezes e Lactário São José ${ }^{8}$ com todas as possibilidades de êxito e com campos especializados para prática das alunas.

A Escola recebe o nome de Hermantina Beraldo, no dia 21 de junho de 1946, em homenagem à esposa do então interventor do Estado e criador da Escola, Dr. João Tavares
Correa Beraldo. No dia 29 de junho de 1946, foi nomeada e tomou posse no cargo a primeira diretora da Escola, Celina Viegas, enfermeira diplomada pela Escola de Enfermagem Carlos Chagas (1941), com curso de especialização em Administração de Escolas de Enfermagem e Pedagogia Aplicada à Enfermagem realizado na Universidade de Boston, nos Estados Unidos, Membro da Comissão de Educação ABED, $1^{\text {a }}$ secretária ${ }^{8}$, Diretora eleita durante o II Congresso Nacional de Enfermagem da (UCEB União Católica das Enfermeiras do Brasil) para difundir os valores católicos na Enfermagem brasileira ${ }^{4}$, tendo como colaboradoras Aracy Sette Câmara, vice-diretora, e Umberlina Goulart, professora, ambas diplomadas pela Escola de Enfermagem Carlos Chagas, em Belo Horizonte, Minas Gerais.

Em 13 de novembro de 1946, foi assinado o Decreto $n^{0}$ 1.907/46 e publicado no Diário Oficial de Minas Gerais em 14 de novembro do mesmo ano. Este Decreto definiu a reorganização do Departamento Estadual de Saúde, e a EEHB passou a ser subordinada à Escola de Saúde Pública ${ }^{9}$.

De julho de 1946 a fevereiro de 1947, a Escola se encontrou em período de organização e aquisição de material necessário à sua instalação, após ter vencido vários obstáculos políticos, pois alguns dos interventores de Minas Gerais do referido período não apoiavam as iniciativas para início de seu funcionamento da escola. A despeito das dificuldades de encontrar um espaço físico para instalações, da falta de verbas para adquirir móveis e para alugar uma sede, a Escola foi inaugurada em 8 de março de $1947^{8}$.

0 Regulamento e o Regimento Interno da Escola foram elaborados pelo Dr. Cid Ferreira Lopes, então diretor da Escola de Saúde Pública de Minas Gerais ${ }^{8}$, por Waleska Paixão, diretora à época da Escola de Enfermagem Carlos Chagas (19391948) ${ }^{10}$. 0 processo seletivo de aspirantes ao curso contou com inscrição de trinta candidatas.

A seleção comportava uma série de requisitos: provas escritas de Português, Matemática, História e Geografia. Além das provas, as moças deveriam possuir o diploma de Ginásio ou equivalente. As candidatas aprovadas deveriam apresentar atestado de sanidade física e mental, vacina antivaríola, além de exames laboratoriais (hemograma, glicemia, fator Rh e sorologia para sífilis) ${ }^{8}$.

0 curso inicialmente funcionou com duas turmas: a primeira iniciada em março, e a segunda, em junho de 1947. A primeira turma ficou aguardando o reconhecimento do

Foto 1: $1^{a}$ Sede da Escola de Enfermagem Hermantina Beraldo

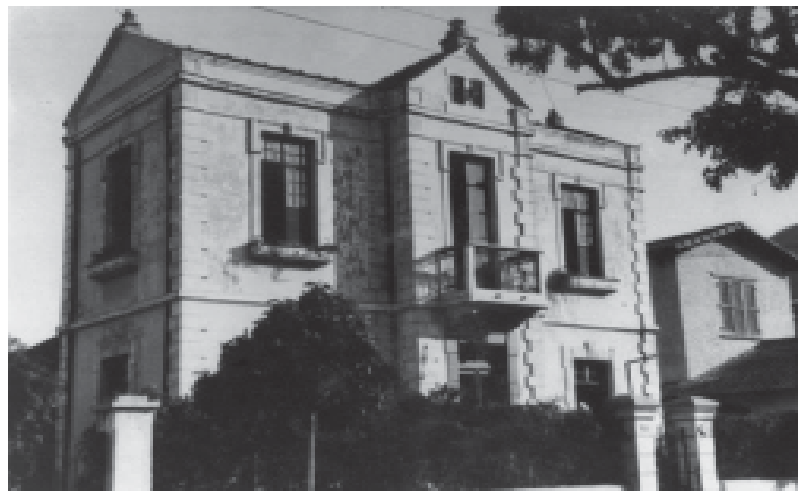


curso, razão pela qual a formatura de ambas, chamadas de "As Pioneiras", aconteceu na mesma época ${ }^{8}$.

A primeira sede da Escola foi instalada na Rua Floriano Peixoto, $n^{0} 535$, Centro de Juiz de Fora - Minas Gerais (Foto 1). A casa possuía dois pavimentos de tamanho pequeno, e permanecia a necessidade de se alugar outro imóvel mais amplo, em que pudessem funcionar os setores administrativos, didáticos e o internato.

Ainda em 1947, a Escola foi transferida para outro imóvel, localizado na Avenida Rio Branco n 3.569. Essa sede da Escola ficou conhecida como a Casa Verde devido à sua pintura externa. $\mathrm{Na}$ Casa Verde, foi instalada a sede administrativa da Escola, na qual funcionava, no primeiro andar, salas de aula, secretaria, sala da diretora, instalação sanitária, quartos das professoras, cozinha, copa e sala de refeições. No segundo andar, havia os quartos das alunas internas e a instalação sanitária8.

Com o passar dos anos, houve crescimento do número de alunas, professoras e funcionários, tendo sido necessário alugar mais outro imóvel para funcionamento da Escola. Em 1949, este imóvel ficou conhecido como Casa Amarela, devido à cor de sua pintura externa, e estava localizado na Avenida Rio Branco $n^{0} 3.550$, próximo à Casa Verde, onde funcionava a biblioteca, o laboratório de dietética e a sala de aula. Ambas as sedes da Escola estavam localizadas a cinco minutos de distância, de caminhada, da Santa Casa de Misericórdia de Juiz de Fora, onde aconteciam as aulas práticas.

A estrutura do currículo apresentava as seguintes disciplinas: Anatomia, Fisiologia, Histologia, Microbiologia, Higiene, Química, Técnica de Enfermagem, Obstetrícia e Higiene Pré-natal, Patologia Cirúrgica, Patologia Médica, Nutrição e Dietoterapia, Terapêutica e Farmacologia, Enfermagem Médica, Enfermagem Cirúrgica, Dieta e Cozinha, Higiene Coletiva e Escolar, Enfermagem das Especialidades, Aspectos Sociais da Enfermagem, Ética - Problemas Morais e Profissionais (incluindo História de Enfermagem), Elementos de Administração Hospitalar, Elementos de Sociologia e Religião Católica. As aulas eram ministradas pelas enfermeiras Celina Viegas, Aracy Sette Câmara, Umbelina Goulart, todas diplomadas pela Escola de Enfermagem Carlos Chagas. Chama atenção que a maioria das disciplinas era ministrada por médicos, dentre eles Dr. João Ribeiro Villaça, Dr. Alvino de Paula Moreira e Dr. Alberto Andrés, provedor da Santa Casa de Misericórdia de Juiz de Fora em 1942-1960. Após o acesso aos conhecimentos e a participação das aulas práticas de técnicas no laboratório, as alunas eram liberadas para o principal campo de estágio, as Clínicas de Cirurgia e Clínica Médica na Santa Casa de Misericórdia de Juiz de Fora. As alunas prestavam assistência integral aos hospitalizados no horário da manhã, sob supervisão das professoras de cada clínica. À tarde, aconteciam as aulas teóricas e práticas ${ }^{8}$.

Desde a criação da escola, Celina Viegas sempre se preocupou com a formação moral das alunas. Na construção da identidade da enfermeira diplomada pela Escola, o rigor com a disciplina e a influência da religião são destaques marcantes.

Celina Viegas, egressa da Escola de Enfermagem Carlos Chagas, com formação profissional rígida na Escola de
Enfermagem Hermantina Beraldo, formação moral ligada à religião, valorizava a adoção de normas e condutas rígidas na escola. As condutas eram inerentes à época, segundo as quais, a mulher era criada para obedecer e se manter fiel a um comportamento rígido, pois, diante de qualquer deslize, era censurada pela família e pela sociedade ${ }^{8}$.

No que se refere às normas, pode-se destacar que havia rigidez quanto à disciplina no espaço acadêmico, inculcando um padrão de comportamento nas alunas, o que não diferia dos adotados pelas demais Escolas de Enfermagem do país. As alunas eram jovens moças, oriundas de cidades do interior, e o comportamento disciplinar era uma responsabilidade perante a família e a sociedade da época ${ }^{8}$.

Em 12 de julho de 1950, a escola teve seu curso reconhecido através do decreto-lei $n^{0} 28.376^{11}$.

\section{AS DIPLOMADAS ("AS PIONEIRAS") PELA ESCOLA DE ENFERMAGEM HERMANTINA BERALDO: SEUS EMBLEMAS E RITUAIS}

As fotografias utilizadas no estudo retratam em sua maioria a formatura das $1^{\mathrm{a}}$ e $2^{\mathrm{a}}$ turmas de enfermeiras diplomadas. A descrição das fotografias selecionadas permitiu identificar alguns emblemas e rituais apropriados pela Escola, tais como: a touca, o véu, o uniforme, a lâmpada, a bandeira da Escola, a Bandeira Nacional, o broche, a Dama da Lâmpada, rituais religiosos, o juramento e a passagem da lâmpada.

A formatura das duas primeiras turmas de enfermeiras ocorreu em agosto de 1950, com 16 diplomadas, designadas como "As Pioneiras", conforme descrito no convite de formatura da turma. Foi celebrada por meio de eventos religiosos, profissionais e sociais. No dia 13 de agosto de 1950, foi iniciada com a celebração de uma missa de ação de graças, na lgreja de São Mateus, pelo Bispo Diocesano Monsenhor Gustavo Freire, e a colação de grau aconteceu no Salão Nobre da Sociedade de Medicina e Cirurgia de Juiz de Fora, Minas Gerais, localizado na Rua Braz Bernardino nº 69, Centro ${ }^{8}$.

Foto 2: Foto oficial das $1^{a}$ e $2^{a}$ turmas, denominadas "As Pioneiras"

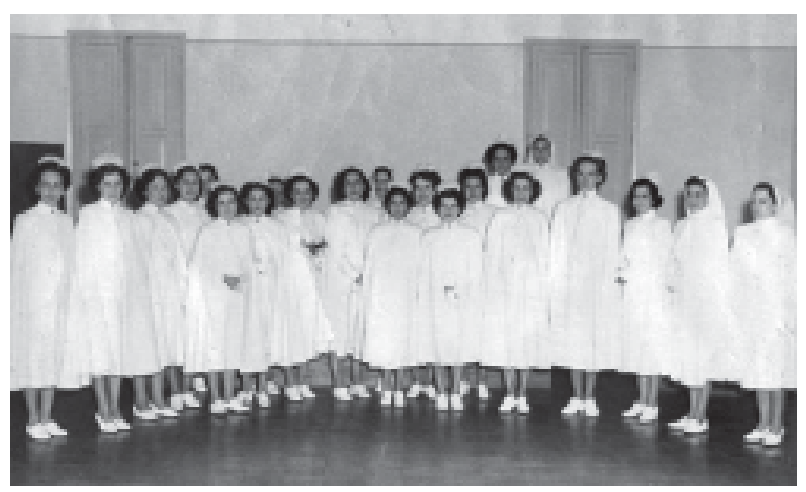

Trata-se da foto oficial das $1^{\mathrm{a}}$ e $2^{\mathrm{a}}$ turmas, denominadas "As Pioneiras", do tipo posada, cujo cenário é o Salão Nobre da Sociedade de Medicina e Cirurgia de Juiz de Fora-Minas Gerais, localizado na Rua Braz Bernardino no 69 - Centro. As integrantes da composição estão com uniforme de cor branca, gola alta e fechada, com a capa e o broche, saia larga e de 
comprimento abaixo dos joelhos, sapato branco de gáspea alta, meias brancas e touca ou véu nos cabelos. 0 uniforme e a touca eram indumentárias que retratavam o grupo ao qual pertenciam as diplomadas, utilizados como parâmetro diferencial de outros grupos, atribuindo direitos e deveres.

$\mathrm{Na}$ Escola de Enfermagem Carlos Chagas, onde Celina Viegas se formou, as enfermeiras tinham como parte da indumentária do uniforme o véu, em vez da tradicional touca de enfermeira, expressando o habitus católico ${ }^{4}$.

Esse revestimento simbólico, o véu, adaptado para a cada situação específica, conferia às mulheres uma credencial de boa moral, pois, desde o século XIX, uma mulher que aparecesse em público com os cabelos expostos era considerada emocional e mentalmente perturbada ou de moral duvidosa ${ }^{12}$.

As três pessoas que estão de véu na composição são professoras, exceto Celina Viegas e as alunas diplomadas que utilizavam toucas, símbolo da identidade da enfermeira. As saias, parte integrante do uniforme, apresentavam comprimento abaixo do joelho, traduzindo o comportamento e a educação feminina da época. Estes trajes traduziam padrões de comportamento condizentes com a futura enfermeira, absorvendo valores atribuídos à mulher pela sociedade. A capa, parte integrante do uniforme de gala, era utilizada em situação de maior destaque social, neste caso a Colação de Grau das $1^{\text {a }}$ e $2^{\mathrm{a}}$ turmas da Escola, denominadas "As Pioneiras".

Ainda com relação aos uniformes, há referências sobre o seu uso e seus significados. Reys, ao ser citada por Coelho ${ }^{13}$, afirma que a enfermeira carecia de sinal exterior e que a tornaria diferente das demais pessoas e que tal sinal obedecia a um princípio superior indicativo de pureza de vida, simbolizado pela cor branca que servia para identificar, de forma indubitável, tanto a presença física da enfermeira quanto o que ela representava.

0 broche era utilizado na formatura, sobre a gola do uniforme, em região central do pescoço. Este emblema tem um triângulo eqüilátero localizado no centro do broche com as seguintes inscrições: na base, contêm o ano de inauguração da Escola, 1947, e a palavra Ideal; nas laterais, as palavras Arte e Ciência sobre os lados do triângulo. 0 círculo menor é preenchido na cor azul escura, e, externamente, ao redor do mesmo, há a seguinte inscrição: Escola de Enfermagem Juiz de Fora. Estes itens descritos estão dispostos sobre uma cruz, circundada por ramos. Este emblema era também utilizado na bandeira da EEHB e em papéis timbrados para difundir de forma legítima a existência da Escola para a sociedade.

0 estudo de Nascimento et al. ${ }^{14}$ cita que o triângulo projetado por Isabel Stewart, enfermeira norte-americana, com as palavras Ciência, Arte e Ideal foi utilizado na primeira capa da Revista Brasileira de Enfermagem e, ainda, durante alguns anos após a criação. Sobre o significado dessas três palavras Nascimento et al. ${ }^{14}$ relatam que a palavra Ciência representa os conhecimentos científicos sobre Enfermagem, Arte representa a aplicação prática dos conhecimentos científicos e, finalmente, a palavra Idea/ refere a necessidade de que a prática esteja aliada à teoria, para que se tenha 0 modelo de enfermeira no qual há toda a perfeição que se possa conceber. Foi possível identificar no centro do triângulo uma lâmpada, um dos emblemas da Enfermagem Moderna.
Coelho refere que, de acordo com Reys, a cruz presente no broche pode ser caracterizada da seguinte forma:

A cruz (...), insígnia que enfermeira (...) traz no broche, mostra o seu amor aos Homens, a sua caridade tão grande, que por amor a eles derramaria seu próprio sangue, se preciso fosse. A cruz rememora a maior prova de amor dada aos Homens, o sacrifício mais completo pelos outros, o esquecimento mais total de si mesmo $0^{13: 140 .}$

Ademais, durante a Era Vargas (1930-1945), a aliança entre o Estado e a lgreja era bastante conhecida; no governo Dutra (19461951) esta relação, no mínimo, era cercada de muita consideração e simpatia. 0 General Eurico Gaspar Dutra teve o cuidado de dar publicidade a sua convicção religiosa 4 . Já em campanha eleitoral, em seu discurso, demonstrou a sua afinidade e consideração com a Igreja Católica, quando falou de "sua fé cristã", citando: "Os brasileiros nascem à sombra da Cruz, e o signo religioso de descoberta faz parte do destino do país e de cada um de seus filhos" ${ }^{15}$. Assim, a presença da Cruz divulga a influência religiosa na formação da enfermeira diplomada pela EEHB.

Ao observar as integrantes da composição, a única aluna que segura a lâmpada é Cecília de Mattos Calanzans, a Dama da Lâmpada, outro emblema apropriado pela EEHB, localizada em posição de destaque na fotografia, próxima ao centro, ao lado da diretora da Escola, Celina Viegas.

A Dama da Lâmpada é um emblema atribuído à aluna de maior destaque da turma durante a graduação, tendo-se como parâmetros os trabalhos escritos, atividades práticas perante a avaliação dos professores e colegas de turma. A influência deste emblema reside na propagação da imagem de um modelo de profissional a ser seguido ${ }^{8}$.

A Foto 3 registra o momento em que o paraninfo da turma A, Dr. João Ribeiro Villaça, enuncia o seu discurso de paraninfo,

Fotos 3: Foto discurso do paraninfo da Turma A, Dr. João Ribeiro Villaça.

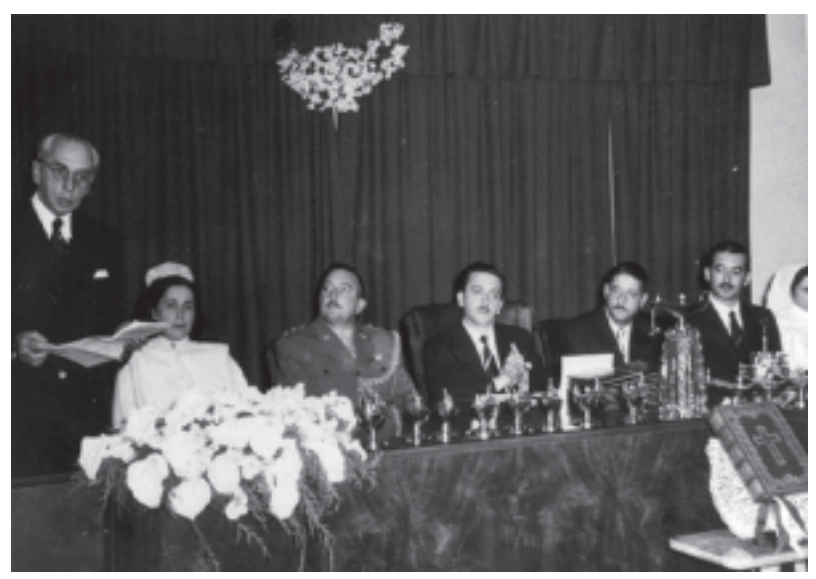

médico chefe da Clínica Cirúrgica da Santa Casa de Misericórdia de Juiz de Fora. A segunda figura da composição é Celina Viegas, diretora da Escola; a terceira é um representante do Exército Brasileiro de alta patente da $4^{a}$ Região Militar (não foi possível identificá-lo); a quarta é o Dr. João Correa Tavares Beraldo, interventor de Minas Gerais à época de criação da Escola; a quinta é o Dr. Olavo Cruz, Secretário Estadual de Saúde de Minas Gerais; e a sexta é o paraninfo da turma B, Dr. Alvino de 
Paula Moreira, médico, Secretário Estadual de Saúde de Minas Gerais, à época do governo do interventor Dr. João Correa Tavares Beraldo. A distribuição dos integrantes da mesa de cerimônia evidencia, como figura central, Dr. João Correa Tavares Beraldo, interventor de Minas Gerais e criador da Escola. Do seu lado direito, uma autoridade militar, e, do seu lado esquerdo, Dr. Olavo Cruz, secretário estadual de saúde de Minas Gerais. Celina Viegas, diretora da EEHB, está ao lado da autoridade militar.

0 texto fotográfico evidencia presenças ilustres e marcantes à cerimônia, autoridades civis, tanto do governo quanto da saúde, além de uma autoridade militar, cujos nomes figuram no convite de formatura, o que demonstra o reconhecimento da Escola à contribuição dessas personalidades ao tempo em que essas presenças conferem prestígio às enfermeiras diplomadas pela EEHB, enunciando a importância da Escola na sociedade. É importante frisar a ausência de uma autoridade religiosa na composição da mesa, presença muito comum, por exemplo, nos eventos promovidos pelas Escolas de Enfermagem Anna Nery e pela Escola de Enfermagem Carlos Chagas. No entanto, a religiosidade nota-se presente à cerimônia mediante a presença da Bíblia Sagrada, em posição central, localizada à frente da mesa de cerimônias.

Vale ressaltar que Celina Viegas, vestida com uniforme de enfermeira e uma autoridade militar em traje militar são os únicos componentes da mesa que estão uniformizados. Os médicos e políticos vestiam trajes formais: ternos de cores escuras e gravatas. Nesse sentido, a enfermeira e o militar representam suas instituições, pois o uniforme é um tipo específico de vestimenta para determinadas categorias de indivíduos e identifica-os como pertencentes a um grupo ou uma instituição, caracterizando a figura de quem o está usando. Assim, o uniforme funciona como objeto disciplinador, uma vez que padroniza as atitudes e comportamentos de quem o veste, seja ele uniforme militar, religioso, escolar ou, como no caso em estudo, profissional ${ }^{16}$.

Ao contrário da maioria das roupas civis, o uniforme é com freqüência consciente e deliberadamente simbólico. Identifica aquele que o veste como membro de algum grupo e muitas vezes o situa em uma hierarquia; às vezes, fornece informação sobre suas realizações ${ }^{12}$. A touca, objeto máximo de caracterização da figura da enfermeira, fez parte do uniforme da EEHB.

Vêem-se ainda na composição fotográfica flores copo-deleite, decorando a mesa de cerimônia. As flores utilizadas para ornamentação representam símbolo de pureza e refinamento, utilizado para demonstrar estima e amizade muito profundas.

Observando ainda sobre a mesa de cerimônia, nota-se uma lâmpada em destaque, num plano mais elevado. Atribui-se à lâmpada o significado de símbolo da Enfermagem Moderna com base no fato de que a patronese da Enfermagem Científica, Florence Nightingale, percorria, durante a noite, as enfermarias dos campos de batalha da Guerra da Criméia, com uma lâmpada acesa para atender os feridos de guerra e providenciar o enterro dos mortos ${ }^{17}$.

Araújo ${ }^{8}$ citando Viegas pontua que: a lâmpada era um raio de esperança para os feridos e tinha um significado: era a vigília, e a luz era a vida. Por esta razão, a lâmpada simboliza a Enfermagem e o profissional enfermeiro, que deve estar constantemente em vigília.
Além disso, a chama da lâmpada enunciava que os ideais da Enfermagem permaneciam vivos na sociedade, o que implicava um compromisso perene com a profissão, traduzido pelo ideal de dedicação ao serviço ${ }^{1}$. Corroborando esta análise, o convite de formatura da turma "As Pioneiras" reafirmava estes ideais através da seguinte inscrição bíblica na parte inferior da capa: "Não vim para ser servido, mas para servir"... (Mat. 20, 28). Ainda sobre tal inscrição nota-se a forte influência da doutrina católica na formação moral e profissional da enfermeira diplomada pela Escola de Enfermagem Hermantina Beraldo. A partir destas informações, entendo que o espírito de doação e abnegação desponta como parte das exigências àquelas que iriam cuidar do corpo do outro.

0 corpo tornava-se alvo de novos mecanismos de poder, oferecidos como novas formas de saber. Corpos sem queixas, sem ideais, manipuláveis e treináveis para uma causa justa (a de servir o próximo). Corpos sujeitos às regras de conduta rígidas e exigentes, formadoras do espírito da caridade cristã $^{18}$.

Ademais, a presença da lâmpada em destaque, ao ser articulada ao texto de um telegrama datado de 5 de maio de 1953, encaminhado à diretora da Escola de Enfermagem Hermantina Beraldo, cujo teor remete a necessidade de urgência da devolução de uma lâmpada de formatura à Escola de Enfermagem Anna Nery que lhe foi cedida por empréstimo em 8 de agosto de 1950, indica que existiam relações sociais entre as duas Escolas. Além disso, um outro ofício datado de 9 de junho de 1953 ratifica novamente a necessidade da devolução da lâmpada emprestada.

\section{Foto 4: Cerimônia de passagem da lâmpada.}

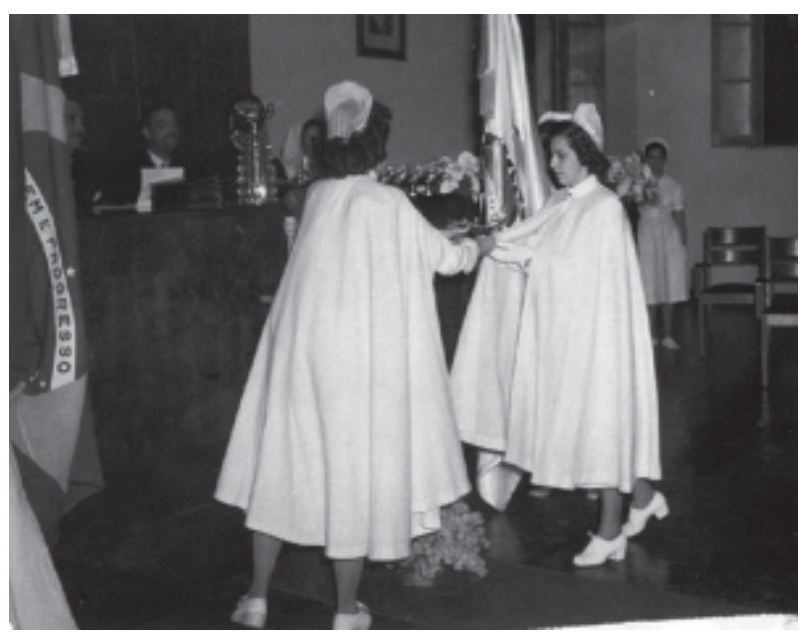

A Foto 4 registra o momento solene em que ocorre realização da passagem da lâmpada por duas alunas diplomadas, o ritual faz parte das atividades desenvolvidas durante a Colação de Grau.

Localizado à esquerda das alunas que realizam a passagem da lâmpada, observa-se a Bandeira Nacional, símbolo pátrio que representa um dos valores difundidos pela Escola, qual seja o patriotismo, coerente com o momento político da época, governo do General Eurico Gaspar Dutra. A propósito, deve-se destacar que o discurso militar conduz o apelo do amor à pátria até com o sacrifício da própria vida. 
Segundo Hobsbwan:

a Bandeira Nacional, 0 Hino Nacional e as Armas Nacionais são os três símbolos através dos quais um país independente proclama sua identidade e soberania. Por isso, eles fazem jus a um respeito e a uma lealdade imediata. Em si já revelam todo o passado, pensamento e toda cultura de uma nação $2: 19$

Atrás das alunas, vê-se outro emblema, a bandeira da Escola. A bandeira representa uma forma da Escola de Enfermagem Hermantina Beraldo proclamar sua identidade perante o campo da educação em Enfermagem e a sociedade local.

Foto 5: Juramento das diplomadas

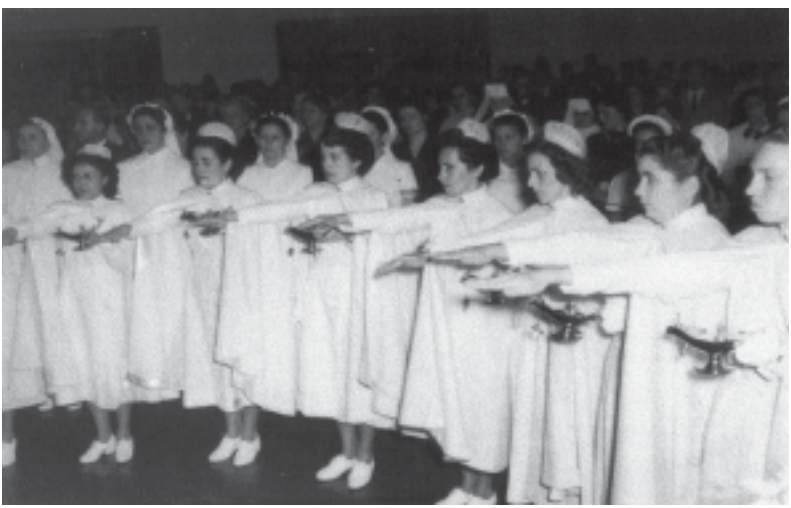

A Foto 5 revela o momento em que as alunas diplomadas realizam o juramento. Com a mão direita estendida e a mão esquerda semiflexionada segurando a lâmpada, as alunas da Escola de Enfermagem Hermantina Beraldo afirmavam o compromisso da futura enfermeira com a profissão, proferindo o juramento, transcrito do convite de formatura (1950):

Solenemente, na presença de Deus e desta Assembléia, sobre os símbolos sagrados de minha fé e de minha Pátria, prometo:

- Praticar com fidelidade minha profissão;

- Dedicar-me com o maior zelo à promoção do bemestar dos doentes a mim confiados;

- Abster-me de tudo quanto for pernicioso ou contrário ao meu dever;

- Não tomar nem ministrar conscientemente drogas nocivas;

- Guardar religiosamente o segredo profissional durante toda a minha vida;

- Auxiliar com inteira lealdade os médicos em seus trabalhos e pesquisas;

A análise detida do teor do juramento evidencia a influência católica na formação de enfermeira, bem como traços de submissão às ordens médicas.

Em segundo plano da foto, há a presença de outras alunas, caracterizada pelas diferenças no uniforme, de professoras utilizando o véu, de freiras que provavelmente são representantes da Santa Casa de Misericórdia (principal campo de estágio das alunas da EEHB); integrantes da sociedade local; e familiares.

A Foto 6 refere-se à participação das alunas da EEHB no Desfile de Comemoração do Centenário da Cidade de Juiz de Fora. 0 evento ocorreu na Avenida Barão do Rio Branco em
Foto 6: Desfile Cívico em Comemoração do Centenário da Cidade de Juiz de Fora.

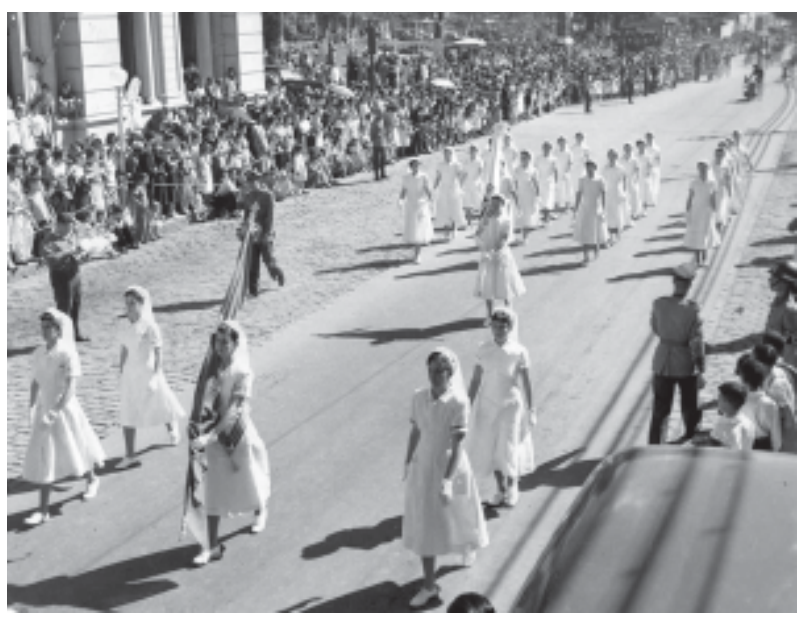

frente à Prefeitura e Parque Halfeld, no centro de Juiz de Fora, em 1950. As alunas da Escola estão envergando o uniforme branco de gala com duas listas na mangas dos vestidos, calçando luvas e utilizando o véu para recobrir os cabelos. Na frente, duas alunas perfiladas à direita, duas alunas perfiladas à esquerda e uma ao centro carregando a Bandeira Nacional. Distante alguns passos, outra aluna ao centro carregando a bandeira da Escola. No final do grupo, quatro fileiras perfiladas com cinco alunas cada, transmitindo uma imagem de disciplina e organização.

A bandeira, outro emblema apropriado pela Escola, desfraldada no evento de demonstração pública, conforme verificado, buscava propagar, por meio de suas inscrições, os princípios ideológicos (Arte, Ciência e Ideal), na busca pelo seu reconhecimento social. Assim, a disposição em mantê-la presente nestes eventos significava legitimar e dar visibilidade à existência da Escola e da Enfermagem em Juiz de Fora, Minas Gerais.

A presença de autoridades militares ao longo da avenida pode ser entendida como um ritual militar onde se expressam afinidades entre as representações legítimas da Enfermagem e o poder militar.

\section{CONSIDERAÇÕES FINAIS}

0 desafio de abordar os emblemas e rituais instituídos pela Escola de Enfermagem Hermantina Beraldo durante 0 processo de formação da turma denominada "As Pioneiras" permitiu compreender que a implantação de um conjunto de "tradições inventadas", consagradas em cerimônias formais, sinalizava uma formação profissional, moral e religiosa rígida, em busca do reconhecimento e visibilidade da enfermeira diplomada pela referida Escola.

Tais emblemas e rituais, ao longo da trajetória da História da Enfermagem no Brasil, passaram a fazer parte do cotidiano das instituições de ensino de Enfermagem. Dentro desta perspectiva, após realizar uma análise das fotos utilizadas no estudo, articuladas a outros documentos escritos, foi possível identificar como emblemas incorporados pela referida escola: 
a touca, o véu, o uniforme, a bandeira da escola, a Bandeira Nacional, a lâmpada, o broche e a Dama da Lâmpada; rituais como: Passagem da Lâmpada, Dama da Lâmpada e juramento da Enfermeira.

Esses rituais e emblemas de inspiração religiosa e militar apontaram modelos a serem seguidos, inculcando atributos como hierarquia e disciplina, favorecendo a construção da identidade enfermeira pela escola.

Através deste estudo foi possível também inferir que existem algumas relações de semelhança e influência do modelo de

\section{Referências}

1. Santos TCF, Barreira IA. 0 poder simbólico da enfermgem norteamericana no ensino da enfermagem na capital do Brasil. Rio de Janeiro(RJ): EEAN/UFRJ; 2002.

2. Hobsbawan E. A invenção das tradições. $2^{a}$ ed. São Paulo(SP): Paz e Terra; 1997.

3. Borges EL, Latini FS, Donoso MTV, Costa TMPF. Reflexões sobre enfermagem pós-Florence. REME: rev min enferm 2000; 4(1/2): 77-82.

4. Almeida Filho AJ. A Escola Anna Nery (EAN) no "front" do campo da educação em enfermagem e o (re) alinhamento das posições de poder: 1931-1949. [tese de doutorado]. Rio de Janeiro(RJ): Escola de Enfermagem Anna Nery/ UFRJ; 2004.

5. Baroni C, Baptista SS. Implantação dos cursos de graduação em enfermagem na década de 70. Rio de Janeiro (RJ); 2002. Mimeo

6. Decreto $n^{0} 20.109$, de 15 de junho de 1931. Regula o exercício de enfermagem no Brasil e fixa as condições para equiparação das escolas de enfermagem e instruções relativas ao processo de exame de revalidação de diploma. In: Enfermagem: legislação e assuntos correlatos. Rio de Janeiro (GB): MS/ Fundação de Serviços de Saúde Pública; 1974.

7. Decreto $n^{0} 1.751$, de 3 de junho de 1946. Organiza o Departamento Estadual de Saúde e cria a Escola de Enfermagem no município de Juiz de Fora. Diário Oficial Estado de Minas Gerais. Belo Horizonte (MG); 1946.

8. Araújo MA. História da Escola de Enfermagem Hermantina Beraldo: gestão Celina Viegas. Belo Horizonte (MG): Escola de Enfermagem/UFMG; 2002.
Enfermagem anglo-americano implementado no início do século XX na capital federal, mediante a criação da Escola de Enfermagem Anna Nery, à conjuntura nacional e invocada pelas escolas de Enfermagem brasileiras, como ideário católico expresso fortemente em vários momentos, além do sentimento patriótico.

Ademais, os resultados apresentados apontam a necessidade de se dar continuidade aos estudos, utilizando referenciais teóricos para construir novas versões sobre os emblemas e rituais instituídos pela escola.

9. Decreto $n^{0} 1.907$, de 13 de junho de 1946. Reorganiza 0 Departamento Estadual de Saúde e passa a Escola de Enfermagem Hermantina Beraldo a ser subordinada diretamente à Escola de Saúde Pública. Diário Oficial do Estado de Minas Gerais. Belo Horizonte (MG); 1946.

10. Nascimento ES, Santos GF, Caldeira VP. Criação, quotidiano e trajetória da Escola de Enfermagem da UFMG: um mergulho no passado... Belo Horizonte(MG): SEGRAC; 1999.

11. Decreto $n^{0} 28.376$, de 12 de julho de 1950. Concede reconhecimento ao curso de enfermagem da Escola de Enfermagem Hermantina Beraldo. In: Brasil. Leis, Decretos, etc. Rio de Janeiro (DF): Imprensa Nacional, 1950.

12. Lurie A. A linguagem das roupas. Rio de Janeiro(RJ): Rocco; 1997.

13. Coelho CP. Escola de Enfermagem Anna Nery: sua história, nossas memórias. Rio de Janeiro(RJ): Cultura; 1997.

14.Nascimento ES, Santos GF, Caldeira VP, Teixeira VMN. Noções sobre enfermeira na revista de enfermagem: reflexão sobre ideal, ciência e arte. Rev Bras Enferm 2002 maio/jun; 55(3): 306 -13.

15. Vale OT. 0 General Dutra e a redemocratização de 45 . Rio de Janeiro(RJ) Civilização Brasileira; 1978.

16. Peres MAA, Barreira IA. Significado dos uniformes de enfermeira nos primórdios da enfermagem moderna. Esc Anna Nery Rev Enferm $2003 \mathrm{abr} ; 7(1): 25-38$.

17. Paixão W. História da enfermagem. Rio de Janeiro(RJ): Bruno Buccini; 1969.

18.Padilha MICS, Nazário NO, Stipp MAC. O legado e o (re) negado: a enfermagem e as ordens/associações religiosas. Texto \& Contexto Enferm 1998; 7(1): 71-89. 